\title{
Purpose-Based Walking Trips by Duration, Distance, and Select Characteristics, 2017 National Household Travel Survey
}

\author{
Kathleen B. Watson, Geoffrey P. Whitfield, Stacey Bricka, and Susan A. Carlson
}

\begin{abstract}
Background: New or enhanced activity-friendly routes to everyday destinations is an evidence-based approach for increasing physical activity. Although national estimates for some infrastructure features surrounding where one lives and the types of nearby destinations are available, less is known about the places where individuals walk. Methods: A total of 5 types of walking trips $(\mathrm{N}=54,034)$ were defined by whether they began or ended at home (home based [HB]) and trip purpose (HB work, HB shopping, HB social/recreation, HB other, and not HB trip) (2017 National Household Travel Survey). Differences and trends by subgroups in the proportion of each purpose-oriented trip were tested using pairwise comparisons and polynomial contrasts. Results: About $14 \%$ of U.S. adults reported $\geq 1$ walking trip on a given day. About $64 \%$ of trips were HB trips. There were few differences in prevalence for each purpose by subgroup. For example, prevalence of trips that were not HB decreased significantly with increasing age and increased with increasing education and household income. Conclusions: Given age-related and socioeconomic differences in walking trips by purpose, planners and other professionals may want to consider trip origin and destination purposes when prioritizing investments for the creation of activity-friendly routes to everyday destinations where people live, work, and play.
\end{abstract}

Keywords: surveillance, epidemiology, active transport

Despite the benefits of regular physical activity, only $54 \%$ of U.S. adults meet the minimal guideline for aerobic physical activity in leisure time. ${ }^{1}$ Walking is an excellent way for most people to be physically active as it requires no special skill or equipment, and it can be done for different purposes, such as walking for leisure or walking to some place (transportation). ${ }^{2}$ Walking behavior is periodically captured as part of national surveillance systems such as the National Health Interview Survey; in 2015, 63\% of adults reported walking for leisure or transportation in the past week, and $32 \%$ specifically reported walking for transportation. ${ }^{3}$

Combining new or enhanced transportation infrastructure (eg, sidewalks) with land use and environmental design interventions (eg, destinations close to potential trip origins) is a recommended approach for increasing physical activity through improvements to the built environment features. ${ }^{4}$ Public health surveillance of the built environment is important for monitoring progress and guiding future efforts to enhance the quality, reach, and equity of this approach. ${ }^{5}$ Perceptions of the built environment have recently been included in national surveillance efforts, and these data have provided national estimates related to the infrastructure surrounding where one lives and the types of accessible destinations that are available nearby. ${ }^{6}$ There is a gap in that less is known about the places (origins and destinations) to or from which individuals walk and the place where individuals walk to or from is guided by their purpose for going to or from that place.

Understanding more about the places where walking trips occur can provide 2 pieces of information, which are keys to implementing

Watson, Whitfield, and Carlson are with the Division of Nutrition, Physical Activity, and Obesity, National Center for Chronic Disease Prevention and Health Promotion, Centers for Disease Control and Prevention, Atlanta, GA, USA. Bricka is with Macrosys, Arlington, VA, USA. Watson (kwatson@cdc.gov) is corresponding author. strategies to create or enhance activity-friendly routes to everyday destinations. First, the place provides information about the activity space - the geographic area within which a person moves or travels during their usual activities. This geographic area includes a person's residential neighborhood; however, there are many other geographies where a person may spend much of their waking time. ${ }^{7}$ For example, over 150 million American adults participate in the labor force, ${ }^{8}$ and the average worker spends a significant amount of the day at a workplace (7.6 $\mathrm{h}$ in 2013).$^{9}$ A person may decide to walk from the worksite to get lunch or dinner or to socialize, thereby the built environment surrounding the worksite (or activity space) may be influential in a person's decision to walk. Second, knowing the places where people walk can help identify the types of destinations where people are more or less likely to walk to. For example, a person may decide to walk to a restaurant to eat a meal but decide to drive to the store to pick up weekly groceries.

Knowledge of the activity space and the place, defined in this study as the purpose or activity performed at the origin or destination of a walking trip, may be useful to researchers, practitioners, and other relevant stakeholders in their efforts to create or enhance activity-friendly routes between everyday destinations. ${ }^{4}$ Understanding differences in trip purpose and destination by distance, duration, and demographic characteristics may be useful in identifying which places to prioritize for pedestrian-friendly improvements to benefit different subgroups. Therefore, the purpose of this study is 2-fold: to describe the prevalence of walking overall and to describe differences in walking trip purpose by duration, distance, and select characteristics.

\section{Methods}

\section{Survey and Analytic Sample}

This study used data from the 2017 National Household Travel Survey (NHTS), a cross-sectional survey of a random sample of 
U.S. households. ${ }^{10}$ The 2017 NHTS used an address-based probability design to create a nationally representative sample of the civilian, noninstitutionalized population. To be eligible to participate in the survey, the household must have had at least one person 18 years of age or older living at the sampled address. ${ }^{11}$

Respondents first completed the recruitment survey which collected brief information about the household and each member, the number of vehicles, contact information, and additional questions about travel behavior. Next, all household members age 5 years and older (adult proxy for children age 5-15 y) completed the retrieval survey - a travel log for each member to record all trips made on the household's assigned travel date. Households were offered a multistage incentive for continued participation in the survey for a maximum incentive of \$27.11 The 2017 NHTS collected data for all members of 129,696 households for an overall response rate of $15.6 \%$ (recruitment survey response rate times the retrieval survey [travel log] response rate). This study included adult respondents aged 18 years and older in these households (all adults in households, $\mathrm{n}=230,942$ ) to examine differences between those who did and who did not report at least one walking trip. To describe differences in walking trip purposes, the study included data from 22,400 adults who reported 72,431 trips made by walking. After excluding 17,051 trips which began and ended in the same place (ie, loop trips) and 1,346 trips which had missing data; the analytic sample for describing differences in walking trip purpose included 54,034 nonloop trips.

\section{Measures}

National Household Travel Survey respondents were classified by sex, age group $(18-34,35-44,45-64$, or $\geq 65$ y), race/ethnicity (non-Hispanic white, non-Hispanic black, Hispanic, or other nonHispanic race), highest level of education completed (high school diploma, General Educational Development [GED], or less; some college/associate degree; Bachelor's degree; or graduate/professional degree), annual household income (less than $\$ 25,000$, $\$ 25,000-\$ 34,999, \$ 35,000-\$ 49,999$, or $\$ 50,000$ or more), Census region (Northeast, Midwest, South, or West), and urban or rural residence. Urban-rural residence designation was determined from the Census Bureau's 2010 urban definition, which is primarily based on residential population density and densely developed territory. ${ }^{12}$ Areas not defined as urban are classified as rural. ${ }^{12}$

The household was randomly assigned 1 day of the week on which each household member 5 years and older was to record travel information for a designated a 24-hour period (Figure 1). For each trip, respondents reported, among other information, the primary trip purpose or activity done at location (eg, home, work, shopping, social; Table 1), mode of transportation (car, bus, walking, etc), and time of day of travel. The NHTS-derived generalized purpose of the trip was based on the purpose of the activity done at the origin (where the person is leaving from) and destination (where the person is going to). The 20 purpose options (Table 1) were classified into the following 5 categories: homebased work, home-based shopping, home-based social/recreation, home-based other, and not home based. ${ }^{13}$ Home-based trips were walking trips where either the origin or the destination was home. A summary of these classifications is presented in Table 2.

Trip minutes were determined by the difference in time between leaving the origin and arriving at the destination. Trip distance (in miles) was estimated from Google Maps API shortestpath route per mode. ${ }^{11}$

\section{Statistical Analyses}

To address the first study aim, initial descriptive analyses included examination of the characteristics of adults with (walkers) and without walking trips (nonwalkers). We used pairwise $t$ tests to identify differences between walkers and nonwalkers for each subgroup characteristics. For the second study aim, we analyzed trip-level data to report the cross-classification of walking trip purpose categories. Walking duration and distance was described using mean walking minutes and miles for each trip purpose. Pairwise $t$ tests were used to identify differences in walking minutes and miles for home-based and not home-based trips and between specific home-based trip purposes (work, shopping, social/recreation, and other). Differences and trends by select characteristics were tested using pairwise comparisons and orthogonal polynomial contrasts, where appropriate. SAS-Callable SUDAAN (version 11.0; Research Triangle Institute, Research Triangle Park, NC) was used for all analyses to account for the complex sampling design and to provide weighted estimates. Level of significance was $P \leq .05$. Bonferroni adjustments were used for multiple comparisons.

\section{Results}

Among all adult respondents, $14.4 \%$ reported at least one walking trip (walkers). There were significant differences in the subgroup distributions between walkers and nonwalkers for nearly all subgroup characteristics examined (Figure 2). Most notably, compared with nonwalkers, walkers were less likely to be non-Hispanic whites (60.5\% vs 65.4\%); adults aged 45 years and older $(45.6 \%$ vs $53.0 \%)$; adults with a high school diploma, GED, or less $(22.3 \%$ vs $27.3 \%$ ); adults with a household income of $\$ 50,000$ or greater (57.4\% vs $61.9 \%)$; adults living in the South $(27.3 \%$ vs $39.1 \%)$; and adults residing in rural areas (7.1\% vs $18.9 \%)$. Among walkers, $19.3 \%$ only reported 1 trip while nearly half $(51.6 \%)$ reported 2 walking trips and $29.1 \%$ reported 3 or more walking trips in a single day.

\section{Walking Trips by Purpose}

Nearly two-thirds $(64.0 \%)$ of trips were home-based indicating they either began or ended at home (Table 2). The most common home-based trip was for social/recreation $(22.9 \%)$, followed by shopping $(19.9 \%)$, other purpose $(15.0 \%)$, and work $(6.2 \%)$. The remaining $36.0 \%$ of trips did not include home as the origin or destination.

\section{Walking Trip Minutes and Distance}

Overall, the average walking trip was 11.9 minutes per trip (Table 3). Minutes for home-based trips (12.8 min) were significantly greater $(P<.001)$ than trips which did not include the home (10.3 min). When examining specific purposes for home-based trips, minutes spent walking for work (14.6 min) and shopping trips $(13.5 \mathrm{~min})$ was significantly greater $(P<.001)$ than trips made for social/recreation purpose.

Overall, the average distance per walking trip was 0.6 miles. The distance between home-based trips and trips which did not begin or end at home were not significantly different. Among home-based trips, there were no significant differences in distance among the specific home-based purposes (work, shopping, social/ recreation, or other). 


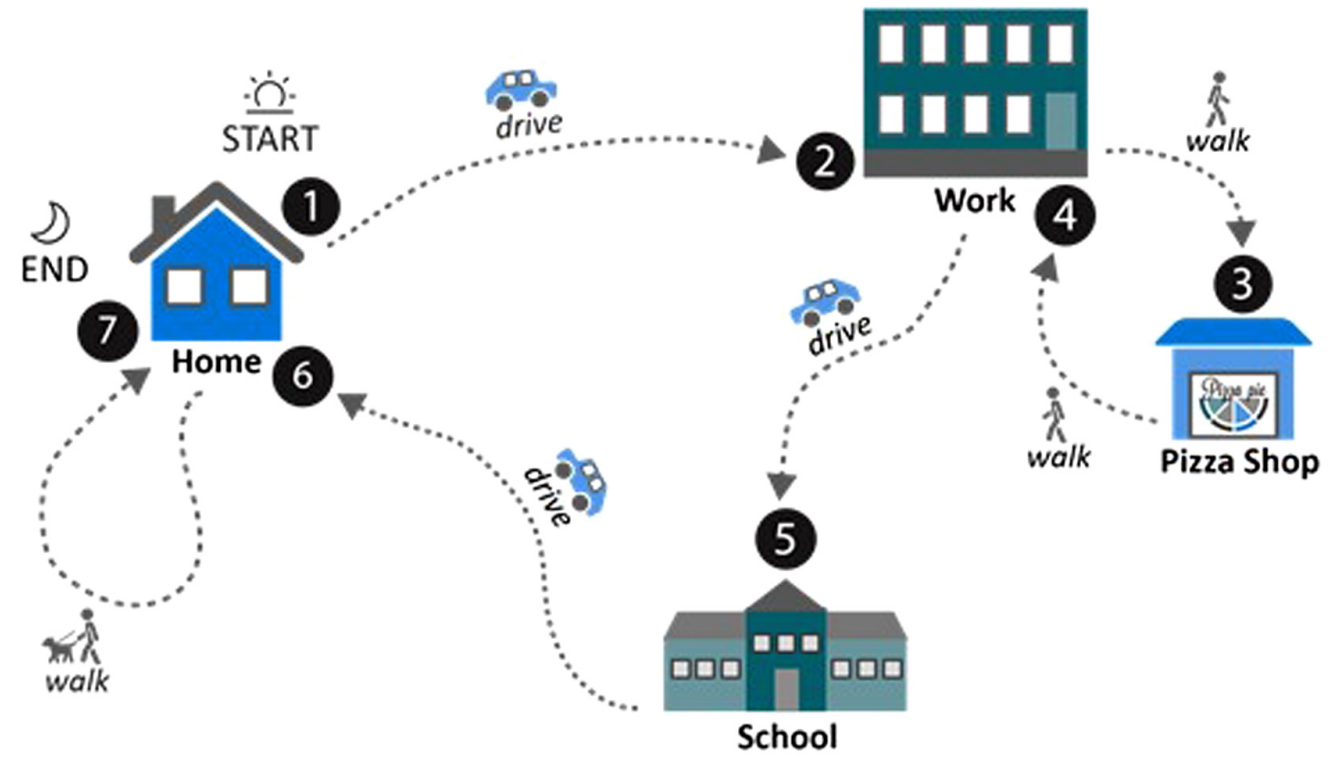

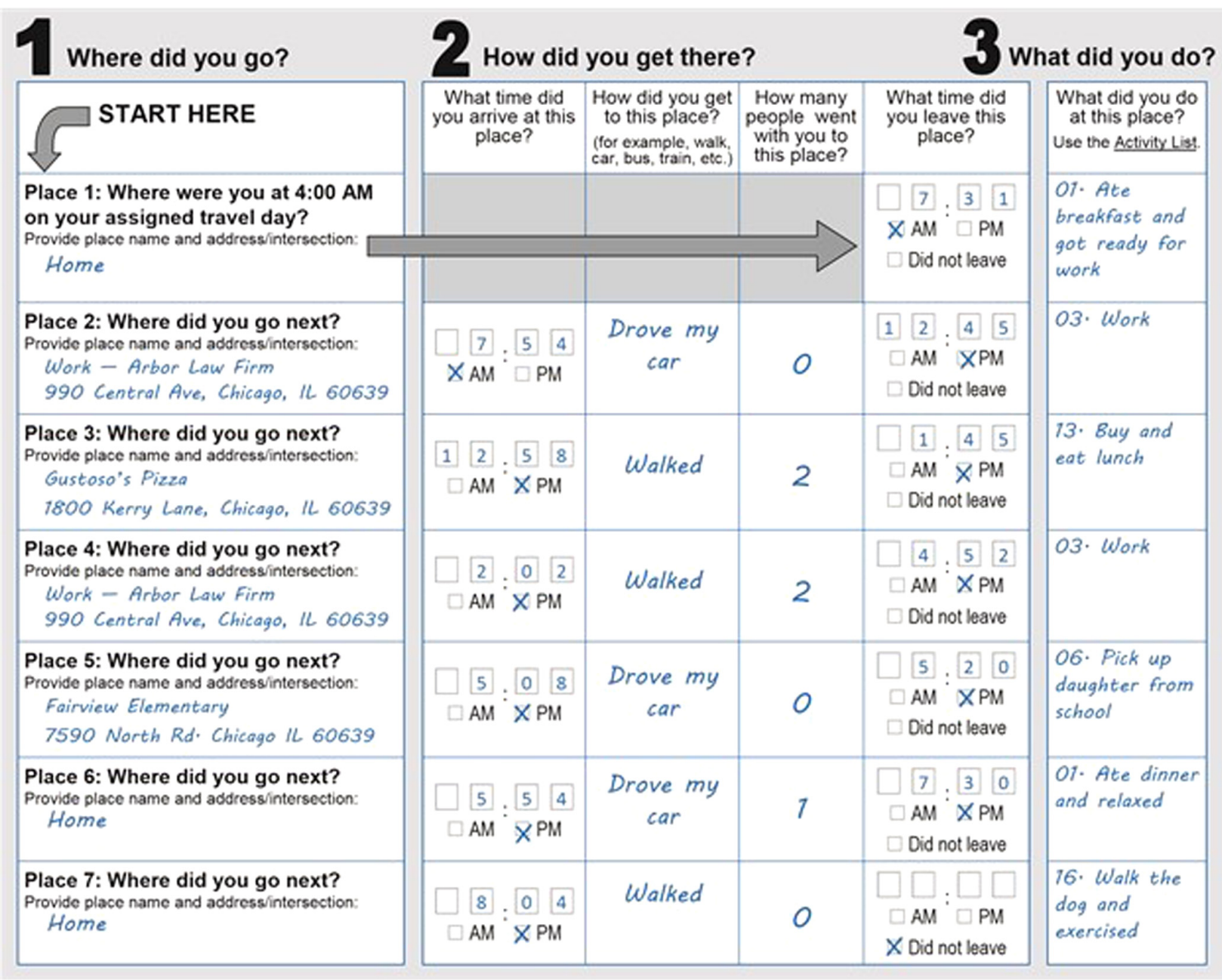

Figure 1 - Full travel log example from the 2017 National Household Travel Survey travel log (reprinted from https://nhts.ornl.gov/assets/2016/ NHTS2017_TravelLog.pdf).

\section{Walking Trips by Selected Characteristics}

Walking trip prevalence by characteristics (Table 4) showed walking was higher for males $(\mathrm{M})$ than females $(\mathrm{F})$ for home- based trips to/from work (M: 7.4, F: 5.3, $P<.001)$ and was higher for females than males for home-based trip to/from other places (M: 12.7, F: 16.9, $P=.003)$. Prevalence was higher for home-based 
Table 1 Activity List From Which the Respondent Could Choose as the Activity Done at the Location

\begin{tabular}{ll}
\hline Major activity category & \multicolumn{1}{c}{ Major activity category } \\
\cline { 1 - 2 } More detailed activity & Other \\
\hline Home & Volunteer activities (not paid) \\
Regular home activities (chores and sleep) & Drop off/pick up someone \\
Work from home (paid) & Change type of transportation \\
Work & Attend school as a student \\
Work & Attend childcare \\
Work-related meeting/trip & Attend adult care \\
Shopping & Other general errands (post office and library) \\
Buy goods (groceries, clothes, appliances, and gas) & Health care visit (medical, dental, and therapy) \\
Buy services (dry cleaners, banking, service a car, and pet care) & Religious or other community activities \\
Buy meals (go out for a meal, snack, and carryout) & Something else \\
Social & \\
Recreational activities (visit parks, movies, bars, and museums) & \\
Exercise (go for a jog, walk, walk the dog, and go to the gym) & \\
Visit friends or relatives & \\
\hline
\end{tabular}

Table 2 Frequency of Walking Trips by Origin and Destination Purpose

\begin{tabular}{|c|c|c|c|c|c|c|}
\hline \multirow[b]{2}{*}{ Origin (Why from) } & \multicolumn{5}{|c|}{ Destination (Why to) } & \multirow[b]{2}{*}{ Proportion } \\
\hline & Home & Work & Shop & Social & Other & \\
\hline Home & $\begin{array}{c}1.0 \\
\text { Home-based } \\
\text { other }\end{array}$ & $\begin{array}{c}3.3 \\
\text { Home-based } \\
\text { work }\end{array}$ & $\begin{array}{c}9.4 \\
\text { Home-based } \\
\text { shopping }\end{array}$ & $\begin{array}{c}11.7 \\
\text { Home-based } \\
\text { social/recreation }\end{array}$ & $\begin{array}{c}7.3 \\
\text { Home-based } \\
\text { other }\end{array}$ & $\begin{array}{l}64.0 \\
\text { Home-based trip for any purpose }\end{array}$ \\
\hline Work & $\begin{array}{c}2.9 \\
\text { Home-based } \\
\text { work }\end{array}$ & 1.7 & 4.1 & 1.2 & 1.3 & $\begin{array}{c}36.0 \\
\text { Not a home-based trip }\end{array}$ \\
\hline Shop & $\begin{array}{c}10.5 \\
\text { Home-based } \\
\text { shopping }\end{array}$ & 4.0 & 6.0 & 1.7 & 1.8 & \\
\hline Social & $\begin{array}{c}11.2 \\
\text { Home-based } \\
\text { social/recreation }\end{array}$ & 0.7 & 2.2 & 3.1 & 1.0 & \\
\hline Other & $\begin{array}{c}6.7 \\
\begin{array}{c}\text { Home-based } \\
\text { other }\end{array}\end{array}$ & 1.1 & 2.5 & 1.1 & 2.5 & \\
\hline
\end{tabular}

Description of activities performed at origin/destination: Home—regular home activities (chores and sleep), work from home (paid); Work-work, work-related meeting/ trip; Shopping - buy goods (groceries, clothes, appliances, and gas), buy services (dry cleaners, banking, service a car, and pet care), and buy meals (go out for a meal, snack, and carryout); social-recreational activities (visit parks, movies, bars, and museums), exercise (go for a jog, walk, walk the dog, and go to the gym), and visit friends or relatives; other-volunteer activities, drop off /pick up someone, change type of transportation, attend school as a student, attend child care, attend adult care, other general errands (post office and library), health care visit (medical, dental, and therapy), and religious or other community activities, something else. Note: Loop trips (trips with the same address for origin and destination) were not included.

social/recreation walking trips and lower for home-based work trips with older age $(P$ for trend $<.001)$; prevalence for walking trips which did not begin or end at home (not home based) was lower with older age. Prevalence of home-based shopping trips was higher while the prevalence for home-based social/recreation trips was lower for adults who were non-Hispanic black compared with non-Hispanic white $(P<.001)$. Patterns in the prevalence of walking tips by purpose were similar between education and household income levels. Prevalence of home-based shopping trips and other home-based trips decreased as education and income increased $(P$ for trend $<.001)$. The prevalence of walking trips which did not begin or end at home (not a home-based trip) increased with increasing education and household income ( $P$ for trend $\leq .001$;
Table 4). Walking trips from the Northeast (vs South and West) region were more likely to be home-based shopping trips and less likely (vs Midwest, South, and West) to be home-based social/ recreation trips. Trips reported by adults living in urban (vs rural) areas were more likely to be home-based shopping trips and less likely to be home-based social/recreation trips. No other significant differences were observed (Table 4).

\section{Discussion}

Overall, nearly two-thirds of walking trips began or ended at home - suggesting efforts which focus on the built environment to improve activity spaces in residential areas is a reasonable strategy 
to increase walking. However, nearly one-third of walking trips occurred around places with origin and destinations other than the home. These findings indicate the built environment around these everyday destinations (worksites, places to shop, and places to socialize) may also benefit from efforts to improve these activity spaces through activity-friendly routes.

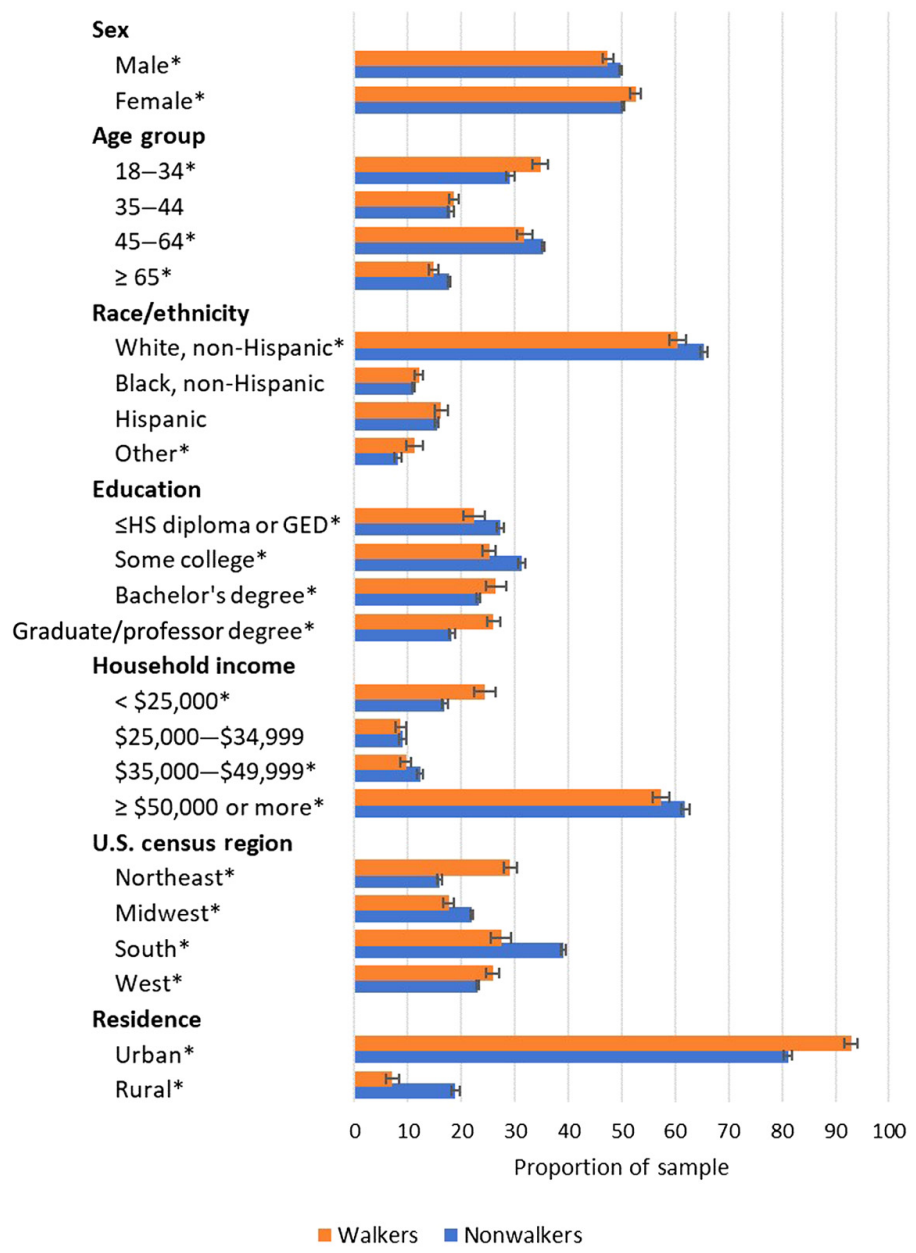

Figure 2 - Distribution of selected characteristics for adults who did (walkers) and who did not (nonwalkers) report at least one walking trip. *Significant differences in the sample proportions between walkers and nonwalkers. Error bars represent $95 \%$ confidence intervals.
Although there were significant differences in walking duration by purpose, the average time spent walking was between 10 and 15 minutes per trip depending on trip purpose. The average trip distance of 0.6 miles did not vary across trip purpose. These findings are consistent with previous research which reported that around $75 \%$ of adults thought walking distances up to one-half mile and up to 10 minutes (short trips) were reasonable and with how an acceptable walking distance has been operationalized (quarter-half a mile ${ }^{14-17}$ and 5-10 $\left.\min ^{14,15}\right)$. Efforts to create new or enhanced transportation infrastructure (eg, sidewalks) combined with land use and environmental design interventions which consider trips within an acceptable walking distance (shorter in duration and distance) have the potential to increase walking, regardless of the trip purpose.

There were few differences in trip purpose by select characteristics. Age, education, and income were associated with the prevalence of trips which began or ended at home as well as activity spaces which did not include the home. Knowing how walking trips differ by the trip purpose and characteristic of the individual (eg, age group and socioeconomic status) can help decision makers better target infrastructure improvements more relevant to disparate populations that could result in more walking trips for those groups. For example, trips by younger adults were less likely than trips by older adults to be between home and places to socialize or recreate. Investigating the distribution of places to socialize near higher density areas of younger adults may be one way for decision makers to determine whether creating more places to socialize near the home, such as having a park, may increase walking among young adults.

We examined trips categorized by the purpose of the activity and whether the trip began or ended at home. Although there is little evidence on walking trips for these purposes by select characteristics, a study from Canada examined trips by origin, destination, and purpose. ${ }^{18}$ The study found the most common walking trip origin and destination was the home, and the most common walking trip purpose was shopping among Canadian adults. ${ }^{18}$ Our study also found home-based trips were the most common; among home-based trips, social/recreation and shopping were the first and second most common purpose. The average walking trip, for any purpose, among Canadian adults was 0.34 miles $(0.67 \mathrm{~km})$ and lasted 9 minutes, ${ }^{18}$ whereas our study found walking trips, for any purpose, were an average of 0.6 miles and lasted an average duration of 12.8 minutes. Why adults in our study took longer trips (in miles and minutes) than the Canadian adults is unclear. However, adults from the Canadian study were from a large metropolitan area (Halifax), ${ }^{18}$ whereas adults in our study were from a wide range of locales and this may explain the difference in trip length and duration. Understanding more about the distances of

Table 3 Mean Distance (in Miles) and Duration (in Minutes) Per Walking Trip by Trip Purpose

\begin{tabular}{|c|c|c|c|c|}
\hline \multirow[b]{2}{*}{ Trip purpose } & \multicolumn{2}{|c|}{ Minutes per trip } & \multicolumn{2}{|c|}{ Miles per trip } \\
\hline & M (SE) & M (SE) & M (SE) & M (SE) \\
\hline Trips (any purpose) & $11.9(0.2)$ & & $0.6(0.1)$ & \\
\hline Home-based trips (any purpose) & $12.8(0.3)^{\mathrm{x}}$ & & $0.6(0.1)$ & \\
\hline Work & & $14.6(1.0)^{\mathrm{x}}$ & & $1.2(0.6)^{\mathrm{b}}$ \\
\hline Shopping & & $13.5(0.3)^{\mathrm{x}}$ & & $0.6(0.2)$ \\
\hline Social/recreation & & $11.7(0.3)^{\mathrm{y}}$ & & $0.5(0.0)$ \\
\hline Other & & $12.9(0.7)$ & & $0.6(0.0)$ \\
\hline Not a home-based trip & $10.3(0.2)^{\mathrm{y}}$ & & $0.5(0.1)$ & \\
\hline
\end{tabular}

${ }^{\mathrm{a}}$ Excluded outliers for miles $(\mathrm{n}=17)$ and minutes $(\mathrm{n}=511)$ from mean estimates; home-based trips begin or end at the home; superscript letters ( $\mathrm{x}$ and $\left.\mathrm{y}\right)$ indicate significant differences: within subgroups, values that share a letter are not significantly different. ${ }^{\text {b }}$ Unstable estimate (relative SE $>30 \%$ ). 
Table 4 Prevalence of Walking Trip Purpose by Select Characteristics

\begin{tabular}{|c|c|c|c|c|c|c|c|}
\hline \multirow[b]{3}{*}{ Characteristics } & \multirow{3}{*}{$\begin{array}{l}\text { Unweighted } \\
\\
\text { Sample } \\
\text { size } \\
\mathbf{n}\end{array}$} & \multicolumn{5}{|c|}{ Home based } & \multirow[b]{3}{*}{$\begin{array}{c}\text { Not home } \\
\text { based } \\
(n=20,334) \\
\%(S E)\end{array}$} \\
\hline & & \multirow[b]{2}{*}{$\begin{array}{c}\text { Any home-based } \\
\text { purpose } \\
(n=33,700) \\
\%(S E)\end{array}$} & \multicolumn{4}{|c|}{ Specific purpose } & \\
\hline & & & $\begin{array}{c}\begin{array}{c}\text { Work } \\
(n=2845)\end{array} \\
\% \text { (SE) }\end{array}$ & $\begin{array}{l}\text { Shopping } \\
\frac{(n=8725)}{\%(\text { SE) }}\end{array}$ & $\begin{array}{c}\begin{array}{c}\text { Social/ } \\
\text { recreation } \\
(\mathrm{n}=15,271)\end{array} \\
\%(\mathrm{SE})\end{array}$ & $\frac{\begin{array}{c}\text { Other } \\
(\mathrm{n}=6859)\end{array}}{\%(\mathrm{SE})}$ & \\
\hline Total & 54,034 & $64.0(0.6)$ & $6.2(0.4)$ & $19.9(1.0)$ & $22.9(0.7)$ & $15.0(0.6)$ & $36.0(0.6)$ \\
\hline \multicolumn{8}{|l|}{ Sex } \\
\hline Male & 24,708 & $64.0(1.0)$ & $7.4(0.5)^{\mathrm{x}}$ & $20.9(1.1)$ & $22.9(1.3)$ & $12.7(0.9)^{\mathrm{x}}$ & $36.0(1.0)$ \\
\hline Female & 29,326 & $64.1(0.9)$ & $5.3(0.5)^{\mathrm{y}}$ & $19.0(1.3)$ & $22.9(0.6)$ & $16.9(1.0)^{\mathrm{y}}$ & $35.9(0.9)$ \\
\hline \multicolumn{8}{|l|}{ Age group, y } \\
\hline $18-34$ & 12,436 & $62.3(2.2)^{\mathrm{L}}$ & $8.9(0.8)^{\mathrm{L}}$ & $18.8(1.7)$ & $19.6(1.9)^{\mathrm{L}}$ & $15.0(1.2)$ & $37.7(2.2)^{\mathrm{L}}$ \\
\hline $35-44$ & 7873 & $62.3(1.8)$ & $5.3(1.0)$ & $18.5(1.2)$ & $20.1(0.9)$ & $18.4(1.4)$ & $37.7(1.8)$ \\
\hline $45-64$ & 20,366 & $65.0(0.8)$ & $5.5(0.6)$ & $21.1(1.3)$ & $26.3(1.0)$ & $12.2(1.1)$ & $35.0(0.8)$ \\
\hline$>65$ & 13,359 & $68.3(1.4)$ & $2.7(0.6)$ & $22.1(1.4)$ & $27.2(1.9)$ & $16.4(1.2)$ & $31.7(1.4)$ \\
\hline \multicolumn{8}{|l|}{ Race/ethnicity } \\
\hline White, non-Hispanic & 41,439 & $63.0(0.9)$ & $6.3(0.5)$ & $18.4(0.8)^{\mathrm{x}}$ & $24.8(0.9)^{\mathrm{x}}$ & $13.6(1.0)$ & $37.0(0.9)$ \\
\hline Black, non-Hispanic & 3367 & $68.3(2.2)$ & $5.3(1.0)$ & $27.8(2.2)^{\mathrm{y}}$ & $16.7(2.2)^{\mathrm{y}}$ & $18.4(2.5)$ & $31.7(2.2)$ \\
\hline Hispanic & 3882 & $66.2(2.6)$ & $6.2(1.0)$ & $22.1(3.2)$ & $19.9(1.9)$ & $18.1(1.6)$ & $33.8(2.6)$ \\
\hline Other $^{\mathrm{b}}$ & 5346 & $61.8(3.1)$ & $7.4(1.5)$ & $16.8(2.0)$ & $22.9(3.1)$ & 14.7 (1.6) & $38.2(3.1)$ \\
\hline \multicolumn{8}{|l|}{ Education } \\
\hline $\begin{array}{l}\text { High school diploma, } \\
\text { GED, or less }\end{array}$ & 8975 & $76.2(1.2)^{\mathrm{L}}$ & $7.1(0.6)$ & $27.3(1.3)^{\mathrm{L}}$ & $21.0(2.2)$ & $20.9(1.3)^{\mathrm{L}}$ & $23.8(1.2)^{\mathrm{L}}$ \\
\hline $\begin{array}{l}\text { Some college/associate } \\
\text { degree }\end{array}$ & 12,700 & $66.6(1.7)$ & $7.2(1.3)$ & $20.0(1.6)$ & 22.5 (1.6) & $16.9(1.6)$ & $33.4(1.7)$ \\
\hline Bachelor's degree & 15,326 & $58.6(1.4)$ & $5.4(0.8)$ & $16.5(1.6)$ & $25.5(1.5)$ & $11.1(0.4)$ & $41.4(1.4)$ \\
\hline $\begin{array}{l}\text { Graduate/professional } \\
\text { degree }\end{array}$ & 17,033 & $57.0(1.1)$ & $5.6(0.8)$ & $17.2(1.6)$ & $22.1(1.2)$ & $12.1(0.8)$ & $43.0(1.1)$ \\
\hline \multicolumn{8}{|l|}{ Household income } \\
\hline Less than $\$ 25,000$ & 10,492 & $73.7(1.8)^{\mathrm{L}}$ & $6.4(1.1)^{\mathrm{L}}$ & $28.1(1.6)^{\mathrm{L}}$ & $17.6(1.2)^{\mathrm{L}}$ & $21.8(1.4)^{\mathrm{L}}$ & $26.3(1.8)^{\mathrm{L}}$ \\
\hline$\$ 25,000-\$ 34,999$ & 3890 & $67.4(3.9)$ & $8.8(1.8)$ & $19.4(2.4)$ & $20.2(2.2)$ & $18.9(3.3)$ & $32.6(3.9)$ \\
\hline$\$ 35,000-\$ 49,999$ & 4922 & $67.1(1.7)$ & $9.2(1.3)$ & $19.4(1.6)$ & $23.9(2.9)$ & $14.5(1.5)$ & $32.9(1.7)$ \\
\hline$\$ 50,000$ or more & 34,730 & $58.6(0.8)$ & $5.4(0.4)$ & $16.4(0.9)$ & $25.5(0.8)$ & $11.4(0.6)$ & $41.4(0.8)$ \\
\hline \multicolumn{8}{|l|}{ U.S. census regions } \\
\hline Northeast & 12,175 & $62.8(1.1)$ & $6.5(0.9)$ & $22.8(1.1)^{\mathrm{x}}$ & $17.8(1.1)^{\mathrm{x}}$ & $15.8(0.9)$ & $37.2(1.1)$ \\
\hline Midwest & 7043 & $65.9(2.6)$ & $6.5(1.0)$ & $21.4(2.3)$ & $24.1(2.1)^{\mathrm{y}}$ & $13.9(0.8)$ & $34.1(2.6)$ \\
\hline South & 16,639 & $65.3(1.2)$ & $6.2(0.5)$ & $17.2(1.5)^{\mathrm{y}}$ & $26.0(1.5)^{\mathrm{y}}$ & $15.9(1.8)$ & $34.7(1.2)$ \\
\hline West & 18,177 & $62.9(1.3)$ & $5.9(0.9)$ & $18.1(0.9)^{\mathrm{y}}$ & $25.2(1.4)^{\mathrm{y}}$ & $13.7(1.2)$ & $37.1(1.3)$ \\
\hline \multicolumn{8}{|l|}{ Residence } \\
\hline Urban & 47,148 & $63.9(0.8)$ & $6.1(0.5)$ & $20.5(1.0)^{\mathrm{x}}$ & $22.3(0.7)^{\mathrm{x}}$ & $15.0(0.6)$ & $36.1(0.8)$ \\
\hline Rural & 6886 & $66.3(3.7)$ & $8.2(1.2)$ & $12.3(3.6)^{\mathrm{y}}$ & $31.0(2.8)^{\mathrm{y}}$ & $14.8(3.1)$ & $33.7(3.7)$ \\
\hline
\end{tabular}

${ }^{\mathrm{a}}$ Superscript letters ( $\mathrm{x}$ and $\mathrm{y}$ ) indicate significant differences: within subgroups, values that share a letter are not significantly different; superscript letter $\mathrm{L}$ (linear) denotes significant linear trend. ${ }^{\mathrm{b}}$ Other race/ethnicity includes Asian, American Indian or Alaska Native, Native Hawaiian or other Pacific Islander, multiple races selected, and some other race selected; not included in race/ethnicity pairwise comparisons.

purpose-based trips, people take can help inform strategies to promote active travel to everyday destinations. For example, one strategy to promote walking may be to improve access to locations for shopping or socializing in close proximity to the workplace.

Although we found no studies examining different types of walking trip purposes by respondent characteristics, several studies reported on the characteristics of adults who walked from home to work. ${ }^{19-21}$ Unlike our study, several studies found adults who walked to work were more likely to have lower education levels ${ }^{20,21}$ and income. ${ }^{21}$ However, similar to our study, commuting to work by walking decreased with increasing age. ${ }^{19}$ Another study conducted in England by Dalton et $\mathrm{al}^{20}$ found no difference by age. Although the reason for the differences in our study is unclear, it may be because our study was not limited to adults who work, and our study included a larger age range (18-92 y) compared with the age range (18-71 y) in the study by Dalton et al. ${ }^{20}$ Information on walking trip purposes by population subgroups could be used to 
help to promote safe routes for persons of different ages in the places they are most likely to be.

This study has limitations and strengths. First, selection bias may be present in a mail-based study. However, research suggests that findings from mail-based studies may be largely equivalent to findings from telephone surveys. ${ }^{22}$ Second, walking minutes per day are self-reported and might be overestimated because of social desirability bias, recall limitations, or other factors. ${ }^{23}$ Third, this study uses the purpose of the walking trip as a proxy for place, as such, we were not able to achieve the same level of specificity to place had we obtained the actual place. Fourth, this study used broad categories for purpose, which also hindered the level of specificity. For example, the purposes for getting a meal and getting groceries were part of the broad category for shopping. Fifth, there may be some confounding due to demographic characteristics or other factors. Finally, our study reports on the purposes of the walking trip but not on what routes were available or accessible. A study on the presence of built environment supports and use or potential use of supports noted differences by subgroups. ${ }^{24}$ If there are no local destinations within a reasonable walking distance, even the best strategies will find it difficult to persuade people to walk. ${ }^{25}$ Future research on routes that included information on availability, quality, and accessibility may help communities better plan and implement strategies which promote walking. A strength of our study is it was drawn from a large, nationally representative sample which allowed us to look at differences by demographic characteristics. Another strength of the study was the diversity of trips; not all walking trips include the activity space around the home.

Understanding the types of locations where adults walk can help guide strategies and initiatives to increase walking. For example, Active People, Healthy Nation ${ }^{\mathrm{SM}}$ is a Centers for Disease Control and Prevention-led initiative to help 27 million Americans become more physically active by 2027 (https://www.cdc.gov/ physicalactivity/activepeoplehealthynation/index.html). ${ }^{26}$ This initiative promotes evidence-based approaches to support physical activity. One such strategy is the promotion of activity-friendly routes to everyday destinations through improved design of communities that make it safe and easy to walk, bicycle, or wheelchair roll for people of all ages and abilities. This is accomplished by connecting routes such as sidewalks, trails, bicycle lanes, and public transit to destinations such as grocery stores, restaurants, schools, worksites, libraries, parks, or health care facilities.

There are many ways communities can be retrofitted to increase walking duration and frequency to that destinations. For example, streets can be retrofitted to promote walking and biking such as adding lighting, landscape buffers, and well-marked crosswalks. ${ }^{27}$ An evaluation of a natural experiment conducted in downtown Vancouver found that retrofitting the urban greenway resulted in increased physical activity and decreased sedentary behavior for those living nearby. ${ }^{28}$ Another example involved the vision of a suburban area in Savannah that included, in part, retrofitting a mall into mixed-use and reimagining green space. ${ }^{29}$ CDC's Connecting Routes to Destinations materials, with realworld examples and an implementation resource guide, can help practitioners implement this strategy (https://www.cdc.gov/ physicalactivity/community-strategies/beactive/index.html). This study found that some purposes varied by population subgroups. This information, coupled with resources for community-based strategies, may be useful to help address inequities in walking behaviors by indicating which types of walking trips may be amenable to increase through activity-friendly routes to everyday destinations.

\section{Conclusions}

Nearly two-thirds of walking trips began or ended at home; opportunities exist to plan and implement strategies to promote walking near where one lives, works, and plays. Given age-related and socioeconomic status differences in some walking trip purposes, planners, professionals and other stakeholders may want to consider these factors when planning, creating, and promoting activity-friendly routes to everyday destinations.

\section{Acknowledgments}

The authors would like to thank Daniel E. Jenkins, P.E., a senior transportation specialist in the Federal Highway Administration's Office of Highway Policy Information, for his contribution to this project. He is the program manager for travel behavior data matters, which includes the NHTS data used in this project.

The findings and conclusions in this report are those of the authors and do not necessarily represent the official position of the Centers for Disease Control and Prevention.

\section{References}

1. Villarroel MA, Blackwell DL, Jen A. Tables of summary health statistics for us adults: 2018 national health interview survey. National Center for Health Statistics. https://ftp.cdc.gov/pub/Health_Statistics/ NCHS/NHIS/SHS/2018_SHS_Table_A-14.pdf. Accessed October 21, 2020.

2. U.S. Department of Health and Human Services, Office of the Surgeon General. Step It Up! The Surgeon General's Call to Action to Promote Walking and Walkable Communities. 2015.

3. Carlson SA, Whitfield GP, Peterson EL, et al. Geographic and urbanrural differences in walking for leisure and transportation. Am J Prev Med. 2018;55(6):887-895. PubMed ID: 30344032 doi:10.1016/j. amepre.2018.07.008

4. Community Preventive Services Task Force. Physical activity: built environment approaches combining transportation system interventions with land use and environmental design. 2016. https://www.thecommunityguide.org/sites/default/files/assets/PABuilt-Environments.pdf. Accessed October 21, 2020.

5. Pate R, Berrigan D, Buchner D, et al. Actions to improve physical activity surveillance in the United States. NAM Perspectives. 2018. Discussion Paper, Washington, DC: National Academy of Medicine.

6. Whitfield GP, Carlson SA, Ussery EN, Watson KB, Berrigan D, Fulton JE. National-level environmental perceptions and walking among urban and rural residents: informing surveillance of walkability. Prev Med. 2019;123:101-108. PubMed ID: 30878571 doi:10. 1016/j.ypmed.2019.03.019

7. Zenk SN, Schulz AJ, Matthews SA, et al. Activity space environment and dietary and physical activity behaviors: a pilot study. Health Place. 2011;17(5):1150-1161. PubMed ID: 21696995 doi:10.1016/j. healthplace.2011.05.001

8. U.S. Department of Labor, Bureau of Labor Statistics. The employment situation. http://www.bls.gov/news.release/empsit.a.htm. Accessed October 29, 2020.

9. U.S. Department of Labor, Bureau of Labor Statistics. American Time Use Survey-2013 Results. 2014.

10. U.S. Department of Transportation, Federal Highway Administration. 2017 National Household Travel Survey. https://nhts.ornl.gov. Accessed June 7, 2019. 
11. Federal Highway Administration Office of Policy Information. 2017 NHTS Data User Guide. 2019.

12. U.S. Department of Commerce Economics and Statistics Administration, U.S. Census Bureau. Defining Rural at the U.S. Census Bureau: American Community Survey and Geography Brief. 2016.

13. U.S. Department of Transportation, Federal Highway Administration. Derived Variables. 2020.

14. Bartlett R. Testing the "popsicle test:" realities of retail shopping in new "traditional neighbourhood developments." Urban Stud. 2003; 40(8):1471-1485. doi:10.1080/0042098032000094397

15. Carmona M, Tiesdell S, Heath T, Oc T. Public Places, Urban Spaces: The Dimensions of Urban Design. 2nd ed. Burlington, MA: Elsevier Ltd; 2010:143.

16. Daisa J. Traffic, Parking, and Transit-Oriented Development. In: Dittmar H, Ohland G, eds. The New Transit Town: Best Practices in Transit-Oriented Development. Washington, D.C.: Island Press; 2004:120.

17. Ewing R, Hodder R. Best development practices: a primer for smart growth. Environmental Protection Agency Smart Growth Network. 2014. http://www.epa.gov/dced/pdf/bestdevprimer.pdf. Accessed January 12, 2021.

18. Millward H, Spinney J, Scott D. Active-transport walking behavior: destinations, durations, distances. J Transp Geogr. 2013;28:101-110. doi:10.1016/j.jtrangeo.2012.11.012

19. Adams EJ, Bull FC, Foster CE. Are perceptions of the environment in the workplace "neighbourhood" associated with commuter walking? J Transp Health. 2016;3(4):479-484. doi:10.1016/j.jth.2016. 01.001

20. Dalton AM, Jones AP, Panter JR, Ogilvie D. Neighbourhood, route and workplace-related environmental characteristics predict adults' mode of travel to work. PLoS One. 2013;8(6):e67575. doi:10.1371/ journal.pone. 0067575
21. Plaut PO. Non-commuters: the people who walk to work or work at home. Transportation. 2004;31(2):229-255. doi:10.1023/B:PORT. $0000016459.21342 .9 \mathrm{~d}$

22. Link MW, Battaglia MP, Frankel MR, Osborn L, Mokdad AH. Address-based versus random-digit-dial surveys: comparison of key health and risk indicators. Am J Epidemiol. 2006;164(10): 1019-1025. PubMed ID: 16968861 doi:10.1093/aje/kwj310

23. Sallis JF, Saelens BE. Assessment of physical activity by selfreport: status, limitations, and future directions. Res $Q$ Exerc Sport. 2000;71(suppl 2):1-14. doi:10.1080/02701367.2000. 11082780

24. Carlson SA, Watson KB, Paul P, Schmid TL, Fulton JE. Understanding the demographic differences in neighborhood walking supports. $J$ Phys Act Health. 2017;14(4):253-264. PubMed ID: 28032804 doi:10.1123/jpah.2016-0273

25. The Institutions of Highways and Transportation. Guidelines for Providing for Journeys on Foot. 2000.

26. Fulton JE, Buchner DM, Carlson SA, et al. CDC's Active people, healthy nation(SM): creating an active America, together. $J$ Phys Act Health. 2018;15(7):469-473. PubMed ID: 29932005 doi:10.1123/ jpah.2018-0249

27. ChangeLab Solutions C. Move this way making neighborhoods more walkable and bikeable. https://www.changelabsolutions.org/sites/ default/files/MoveThisWay_FINAL-20130905.pdf. Accessed April 12, 2021.

28. Frank LD, Hong A, Ngo VD. Causal evaluation of urban greenway retrofit: a longitudinal study on physical activity and sedentary behavior. Prev Med. 2019;123:109-116. PubMed ID: 30731094 doi:10.1016/j.ypmed.2019.01.011

29. Steuteville R. Plan to retrofit suburban to mixed-use urban. Public Square: A CNU Journal. 2018. https://www.cnu.org/publicsquare/ 2018/04/02/plan-retrofit-suburban-mixed-use-urban. Accessed April 14, 2021. 